\title{
Atividade inibidora de amilase e protease de milho contra Fusarium verticillioides durante a germinação
}

\section{Amylase and protease inhibition activity against Fusarium verticillioides in corn germination}

\author{
Patrícia Kadozawa ${ }^{1}$; Edson Luíz Zangrando Figueira²; Alberto Luiz Marsaro \\ Júnior; ; Antonio Carlos Gerage ${ }^{4}$; Sonia Maria Noemberg Lazzari ${ }^{5}$; \\ Elisabete Yurie Sataque Ono ${ }^{6}$; Ivone Yurika Mizubuti ${ }^{7}$; Elisa Yoko Hirooka ${ }^{8 *}$
}

\section{Resumo}

Fusarium verticillioides, patógeno primário do milho, destaca-se pela produção da fumonisina, prejudicial à saúde humana e animal. Considerando que os mecanismos naturais de defesa são ferramentas promissoras no controle de fitopatógenos, avaliou-se: a atividade dos inibidores de amilase e protease presente nos híbridos de milho AG 5011 e CD 307 durante a germinação em câmara de germinação $\left(25^{\circ} \mathrm{C}\right.$ e $90-95 \%$ UR) e em casa de vegetação (sem controle de temperatura e umidade) contra amilase e protease de F. verticillioides. Paralelamente, avaliou-se a resistência do milho a Sitophilus zeamais. A atividade inibitória de enzimas avaliada nos tempos $0,24,48,72,96$ e $168 \mathrm{~h}$, aumentou durante a germinação em ambos os híbridos, sendo que a atividade inibidora de amilase variou de 2,8 a 39,5 UIA/g, enquanto que a atividade inibidora de protease variou de 550,0 a 3633,9 UIP/g. Os maiores índices de atividade inibidora foram observados em câmara de germinação, e em CD 307. O híbrido AG 5011 apresentou-se menos susceptível a $S$. zeamais e tendeu a maior atividade inibidora de enzimas no tempo $0 \mathrm{~h}$. Os resultados obtidos indicaram possível desempenho de inibidores enzimáticos na germinação na defesa do milho contra $F$. verticillioides e $S$. zeamais.

Palavras-chave: Zea mays, caruncho, defesa, inibidor de amilase, inibidor de protease

\begin{abstract}
The primary maize pathogen, Fusarium verticillioides (F. moniliforme Sheldon) is responsible for fumonisin production, which is harmful to human and animal health. In addition, maize can be more susceptible to fungal infection after insect attack. The activity of amylase and protease inhibitors in AG 5011 and CD 307 hybrids were determined during germination with controlled and not controlled conditions
\end{abstract}

1 Engenheira Agrônoma, Mestre em Ciência de Alimentos, Depto TAM, UEL-PR.

2 Embrapa Recursos Genéticos e Biotecnologia, Brasília-DF e Doutorado em Ciência de Alimentos, Depto TAM, UEL-PR.

3 Embrapa Roraima, Br 174, Km 8, Boa Vista-RR.

4 Instituto Agronômico do Paraná - IAPAR, Londrina-PR

5 Depto Zoologia, Universidade Federal do Paraná, Curitiba-PR

6 Depto Bioquímica, Centro de Ciências Agrárias, Universidade Estadual de Londrina.

7 Depto Zootecnia, Centro de Ciências Agrárias, Universidade Estadual de Londrina.

8 Depto Tecnol Alimentos e Medicamentos, Centro de Ciências Agrárias, Universidade Estadual de Londrina, Caixa Postal 6001, CEP 86051-990, Londrina-Pr. Tel.: 043-33714565. Fax.: 043-33714080. E-mail: hirooka@uel.br.

* Autor para correspondência 
of temperature and relative humidity and, they were correlated to maize resistance against Sithophilus zeamais. The inhibitory activity during corn germination was evaluated at $0,24,48,72,96$ and $168 \mathrm{~h}$. Amylase and protease inhibitory activity increased during germination in both hybrids, which ranged respectively from 2.8 to $39.5 \mathrm{UIA} / \mathrm{g}$, and 550.0 to $3633.9 \mathrm{UIP} / \mathrm{g}$. The highest levels of inhibitory activity occurred in hybrid CD 307 in germination chamber. The biologic cycle and susceptible rate were evaluated for corn resistance test. The AG 5011 hybrid was less susceptible to S. zeamais and showed higher inhibitory activity (time $0 \mathrm{~h}$ ), demonstrating possible relationship between resistance against the insect and inhibitory enzymes. These results indicated that maize natural defense mechanism plays an important role on phytopathogen control.

Key words: Zea mays, weevil, defense, amylase inhibitor, protease inhibitor

\section{Introdução}

O milho é um cereal essencial com produção mundial de 598,7 milhões de toneladas na safra 2001/ 2002, onde o Brasil participou com produção de 35,2 milhões de toneladas. O consumo do milho se associa intimamente à alimentação animal, com ênfase a aves e suínos. Entretanto, aproximadamente $30 \%$ da produção destina-se diretamente ao consumo humano, originando mais de 500 produtos derivados (LAFIS, 2003).

As características nutricionais expõem o milho ao ataque de fitopatógenos, devendo-se considerar a importância de insetos que favorecem o estabelecimento de fungos toxigênicos. Fusarium verticillioides Sac. Niremberg (Fusarium moniliforme Sheldon), patógeno primário do milho amplamente distribuído na natureza, destaca principalmente em regiões de clima tropical úmido e subtropical (MUNKVOLD; DESJARDINS, 1997; ONO et al., 1999). Este fungo produz micotoxinas do grupo das fumonisinas, que juntamente com as aflatoxinas têm sido motivo preocupante para saúde humana e animal, já que provavelmente está envolvida no processo cancerígeno em humanos (UENO, 2000).

Os inibidores enzimáticos, constituídos de proteínas com atividade contra amilase e protease fúngica presentes naturalmente no milho, representam ferramentas potenciais, capazes de conter o crescimento microbiano e, conseqüente produção de micotoxinas (BLANCO-LABRA et al., 1995; FIGUEIRA et al., 2003 a,b). A atividade potencial das enzimas para o controle de fungos durante a germinação tem sido assunto discutido, visando o melhoramento genético empregando-se a defesa natural das plantas (ELLIOTT et al., 2003). Com a capacidade de atuar sobre enzimas digestivas de fitopatógenos, estes inibidores participariam no mecanismo de defesa abrindo perspectivas promissoras para produção de plantas resistentes ao ataque de fungos (BLANCO-LABRA; ITURBECHIÑAS, 1981; FIGUEIRA et al., 2003 a,b).

O objetivo deste trabalho foi avaliar a atividade dos inibidores de amilase e protease durante a germinação em temperatura e umidade controladas ou não.

\section{Material e métodos}

\section{Material vegetal}

Foram avaliadas sementes dos cultivares de milho AG 5011 e CD 307 sem tratamento com fungicidas, fornecidos pelo Instituto Agronômico do Paraná (IAPAR), Londrina - PR. As sementes de milho foram submetidas ao processo de limpeza manual para eliminar grãos quebrados e ardidos, higienizada com hipoclorito de sódio $2 \%$ durante 5 min e lavada com água estéril.

\section{Germinação em câmara de germinação \\ Cinqüenta sementes foram dispostas simetricamente sobre duas folhas de papel de germinação (papel de filtro $2 \mathrm{~mm}, 38 \times 28 \mathrm{~cm}$ ) previamente umedecidas, cobertas com um papel de}


germinação também umedecida e o conjunto dobrado semelhante a um rolo. A incubação durante 0,24 , 48, 72, 96, $168 \mathrm{~h}$ procedeu-se em câmara de germinação (DE LEO) em condição controlada $\left(25^{\circ} \mathrm{C}\right.$ e $\left.90 \%\right)$. O híbrido $\mathrm{CD} 307$ foi submetido à germinação por $192 \mathrm{~h}$ para análise de atividade inibidora de amilase/protease nas diferentes partes da plântula. Neste ensaio, as amostras foram separadas em três partes: coleóptilo, endosperma e radícula. As demais amostras foram coletadas do germinador nos intervalos mencionados e imediatamente congeladas, liofilizadas e trituradas para granulometria máxima de 48 mesh. O ensaio com três repetições consistiu de seis tratamentos correspondentes a 6 tempos de análise $(0,24,48,72$, 96 e 168 h). Nos ensaios analíticos utilizaram-se triplicatas das repetições, para avaliação estatística dos dados. O experimento com coleóptilo, endosperma e radícula da plântula foi conduzido com três repetições.

\section{Germinação em casa de vegetação}

Cinqüenta sementes foram semeadas em bandejas de isopor para germinação durante $0,24,48,72,96$ e $168 \mathrm{~h}$ sem controle de temperatura e umidade, coletadas e imediatamente congeladas, liofilizadas e trituradas para granulometria máxima de 48 mesh. $\mathrm{O}$ ensaio com três repetições consistiu de seis tratamentos correspondentes a 6 tempos de análise (0 a 168h) para cada híbrido. Nos ensaios analíticos utilizaram-se triplicatas das repetições, para avaliação estatística.

\section{Atividade inibidora de amilase}

As amostras previamente trituradas foram desengorduradas com acetona na proporção 1:1 (m/ v), sob agitação durante $15 \mathrm{~min}$ a temperatura ambiente, decantada e o sobrenadante desprezado. O processo foi repetido 3 vezes e as amostras secas à temperatura ambiente, até a completa evaporação da acetona. Para a extração de inibidores de amilase,
$5 \mathrm{~g}$ de farinha desengordurada foram homogeneizadas com $25 \mathrm{~mL}$ de tampão acetato de sódio $0,1 \mathrm{M}, \mathrm{pH}$ 6,0 a $400 \mathrm{rpm}$ por $90 \mathrm{~min}$ a $4^{\circ} \mathrm{C}$. O sobrenadante obtido foi centrifugado a $30000 \mathrm{xg}$ por $20 \mathrm{~min} \mathrm{a} 4^{\circ} \mathrm{C}$ e dialisado contra água destilada. A atividade inibidora de amilase foi determinada pelo método iodométrico segundo Wilson \& Ingledew (1982).

\section{Atividade inibidora de protease}

A extração de inibidores de protease foi efetuada segundo Blanco-Labra et al. (1995). As amostras previamente trituradas foram desengorduradas com acetona na proporção $1: 1(\mathrm{~m} / \mathrm{v})$, sob agitação por 15 min a temperatura ambiente, decantadas e o sobrenadante desprezado. O processo foi repetido 3 vezes e secas a temperatura ambiente. A amostra desengordurada foi homogeneizada em tampão acetato de sódio $20 \mathrm{mM}, \mathrm{pH} 5,5 \mathrm{com} 1 \mathrm{mM}$ cloreto de cálcio $(1: 5, \mathrm{~m} / \mathrm{v})$ durante $2 \mathrm{~h}$ a $4^{\circ} \mathrm{C}$, centrifugada $\left(10000 \mathrm{xg}\right.$ por $\left.1 \mathrm{~h} \mathrm{a} 4^{\circ} \mathrm{C}\right)$ e no sobrenadante efetuouse a determinação da atividade inibidora de protease pelo método de Kakade et al. (1974), modificado por Liu \& Markakis (1989).

\section{Teste de resistência do milho a Sitophilus zeamais}

O milho limpo e higienizado foi submetido à determinação de umidade segundo Waquim (1992), para posterior padronização da umidade a 13,5\%. As amostras de milho dos híbridos AG 5011 e CD 307 com umidade padronizada foram armazenadas em caixas plásticas transparentes $(8 \times 12 \mathrm{~cm}) \mathrm{com}$ tampa cuja área central $\left(2 \mathrm{~cm}^{2}\right)$ foi cortada e vedada com tela plástica perfurada $(1 \mathrm{~mm})$. A quantidade de $100 \mathrm{~g}$ de cada híbrido de milho foi pesada e colocada em respectivas caixas com 20 carunchos de milho (S. zeamais), sendo 15 fêmeas e 5 machos. Os testes foram realizados com três repetições por híbrido. As caixas foram incubadas a $27^{\circ} \mathrm{C}$ e $70-75 \%$ UR, durante 10 dias para oviposição. Os adultos foram manualmente descartados e os grãos acondicionados novamente nas caixas plásticas por 
30 dias a $27^{\circ} \mathrm{C}$ e $70-75 \%$ UR. Em seguida, procedeuse a contagem e o descarte dos insetos emersos a cada 2 dias até que o número de adultos emerso fosse igual a zero, atingido aos 90 dias. Simultaneamente, os insetos emergidos e os grãos de milho, foram pesados, sendo os parâmetros avaliados: ciclo biológico médio do inseto (CB), número de insetos emersos de grãos (NE), peso de adultos emersos (PE), índice de susceptibilidade de milho (IS), perda de peso dos grãos (PP). O índice de susceptibilidade e o ciclo biológico foram calculados pelas equações de Dobie (1977):

a) Equação do Ciclo Biológico

$\mathrm{CB}=\Sigma \mathrm{XY} / \Sigma \mathrm{X}$

onde: $\mathrm{X}=$ número de adultos emersos; $\mathrm{Y}=$ número de dias após infestação (Ex: 30, 32, 34, 36, 38, 40, ... até 90$) ; \mathrm{XY}=$ resultado da multiplicação de número de adultos emersos e número de dias após infestação; $\mathrm{CB}=$ ciclo biológico médio

b) Equação do Índice de Susceptibilidade

$\mathrm{IS}=[(\ln \Sigma \mathrm{X}) / \mathrm{CB}] \cdot 100$

onde: $\mathrm{X}=$ número de adultos emersos; $\mathrm{CB}=$ ciclo biológico médio; IS= índice de susceptibilidade.

\section{Resultados e Discussão}

Atividade inibidora contra amilase e protease de F. verticillioides na germinação de milho

$\mathrm{O}$ estudo sobre inibidores de amilase e protease se aponta entre pesquisas de destaque direcionado à aplicação do mecanismo natural de defesa contra insetos, visando minimizar a perda de qualidade do milho. Não obstante, as informações deste mecanismo contra fungos micotoxigênicos / fitopatogênicos ainda são escassas, se considerar a indissociável ocorrência e interação entre estes dois grupos de predadores (FAKHOURY; WOLOSHUK, 2001; FIGUEIRA et al., 2003a,b).
Ênfase deve ser dada à defesa durante a germinação de milho, onde inicia a integridade da cadeia produtiva de alimentos. Fakhoury \& Woloshuk (2001) salientaram a contribuição dos inibidores enzimáticos na resistência contra patógenos, assim como pesquisas anteriores demonstraram-se a ação promissora de inibidores de caráter peptídico no controle de $F$. verticillioides (FIGUEIRA et al., 2003a,b).

As Figuras 1 e 2 mostram o comportamento da atividade inibidora de amilase e protease, respectivamente, dos híbridos de milho AG 5011 e CD 307 contra amilase e protease de $F$. verticillioides, no decorrer de 168 h de germinação, conduzidas em condições controladas (câmara de germinação com 90 - $95 \%$ UR e $25^{\circ} \mathrm{C}$ ) e sem controle (casa de vegetação). Na germinação de milho conduzido em casa de vegetação, a temperatura mínima no período oscilou de $9-21^{\circ} \mathrm{C}$ e, a máxima de $21-35^{\circ} \mathrm{C}$ (Figura 3).

O ensaio em câmara de germinação favoreceu a produção de maiores níveis de atividade inibidora de amilase nos híbridos analisados. A atividade dos inibidores de amilase variou de 4,5 a $34,8 \mathrm{UIA} / \mathrm{g}$ no híbrido AG 5011 e 4,4 a 39,5 UIA/g no híbrido CD 307 , com tendência de aumento no decorrer da germinação, quando comparada ao tempo $0 \mathrm{~h}$ (Figura 1). Não obstante, o híbrido CD 307 apresentou pico de atividade inibidora de amilase no tempo de $48 \mathrm{~h}$ em câmara de germinação (Figura 1).

Na câmara de germinação, o híbrido de milho AG 5011 mostrou evolução da atividade inibidora de amilase de 6,$4 ; 2,8 ; 7,5 ; 25,4 ; 20,9$ e $34,8 \mathrm{UIA} / \mathrm{g}$, correspondente aos tempos $0,24,48,72,96$ e $168 \mathrm{~h}$ (Figura 1). O mesmo híbrido, submetido a condições não controladas (germinação em casa de vegetação) apresentou atividades inibidoras de amilase de 6,4; 7,$1 ; 6,4 ; 4,8 ; 4,5$ e $9 ; 5$ UIA/g nos tempos $0,24,48$, 72,96 e $168 \mathrm{~h}$. 


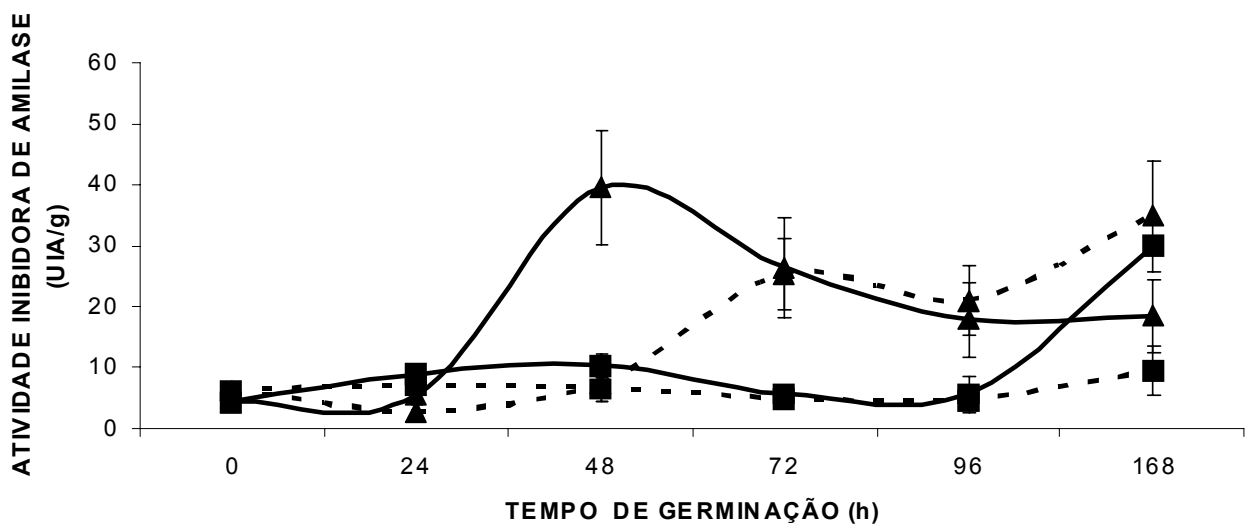

$$
\begin{aligned}
& \text { - ム - AG } 5011 \text { em câmara de germinação - - - AG } 5011 \text { em casa de vegetação } \\
& \text { —CD } 307 \text { em câmara de germinação _L CD } 307 \text { em casa de vegetação }
\end{aligned}
$$

Figura 1. Atividade do inibidor de amilase nos híbridos AG 5011 e CD 307 durante a germinação conduzida em câmara de germinação $\left(25^{\circ} \mathrm{C}\right.$ e $90-95 \%$ UR) e em casa de vegetação (sem controle de temperatura e umidade).

A atividade inibidora de amilase durante a germinação tendeu a aumentar conforme o desenvolvimento da plântula (Figura 1), evoluindo de 4,5 a $34,8 \mathrm{UIA} / \mathrm{g}$. A máxima atividade observou-se no $2^{\circ}$ dia $(48 \mathrm{~h})$ de germinação no híbrido CD 307 com atividade inibidora média de 24,9 UIA/g (Tabela 4). Figueira et al. (2003b) obtiveram atividade inibidora de 11,9 UIA/mg de proteína em grãos de AG 5011 germinados. A atividade inibidora de amilase denota o potencial do milho na defesa contra F. verticillioides, sugerindo maior resistência da plântula no período com máxima atividade (KADOZAWA, 2002).

Comparado ao híbrido de milho AG 5011, o CD 307 apresentou maior atividade inibidora de amilase, indicando comportamento mais promissor perante mecanismo de defesa contra $F$. verticillioides (Figura 1). A escolha do híbrido AG 5011 baseou-se no estudo prévio (FIGUEIRA et al., 2003b) onde estudando 37 híbridos de milho, a máxima atividade inibidora $(15,97 \mathrm{UIA} / \mathrm{g})$ ocorreu neste cultivar. Todavia, o mesmo híbrido no presente trabalho apresentou atividade inibidora de 6,4 UIA/g (Figura 1), indicando que apesar de serem o mesmo genótipo, a diferença nos valores de UIA indicaria variação na amostra, já que as sementes de AG 5011 pertenceram a safras e locais diferentes.
A influência da germinação de milho na produção de proteínas antifúngica tem sido descrita por Cordero et al. (1992), que isolaram proteínas antifúngicas de 23 a $24 \mathrm{kDa}$, com pico médio de atividade no terceiro dia de germinação (72 h). Guo et al. (1997) mostraram que a germinação induziu o acúmulo de proteínas específicas e atividade antifúngica em milho. Chen et al. (2001) detectaram proteínas associadas à resistência à aflatoxina em milho germinado, assim como Elliott et al. (2003) estudaram um inibidor de xilanase ativo sobre enzima de Aspergillus niger.

Os inibidores de protease parecem regular a proteólise das proteínas de reserva durante a germinação e, paralelamente também apresentam ação inibitória sobre proteínas de patógenos (XAVIER FILHO, 1992). Devido a característica bifuncional dos inibidores de protease, supõe-se que a atuação como compostos de defesa na planta seja apenas conseqüência de sua presença na semente (GUO et al., 1997).

Em paralelo ao ensaio com inibidores de amilase, analisou-se o perfil da atividade inibidora de protease nos híbridos AG 5011 e CD 307 submetidos às mesmas condições de germinação (Figura 2). Os resultados de inibidores de protease variaram entre 334,6 a 2695,1 UIP/g e 492,2 a 3817,6 UIP/g para os híbridos AG 5011 
e CD 307, respectivamente (Figura 2). As máximas atividades inibidoras foram detectadas em $168 \mathrm{~h}$ na câmara de germinação (Figura 2). O híbrido de milho
CD 307 apresentou atividades médias significativamente maiores que AG 5011, fenômeno observado também em inibidores de amilase.

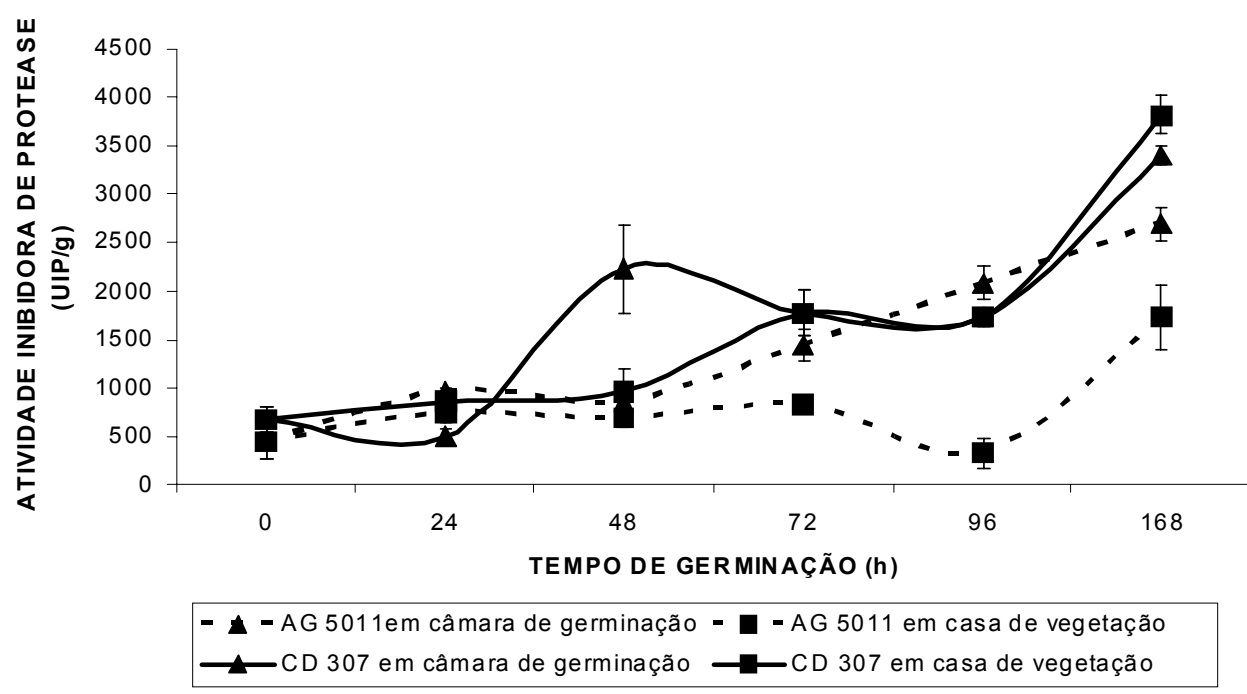

Figura 2. Atividade do inibidor de protease nos híbridos AG 5011 e CD 307 durante a germinação conduzida em câmara de germinação $\left(25^{\circ} \mathrm{C}\right.$ e 90-95\%UR) e em casa de vegetação (sem controle de temperatura e umidade).

Em condições de câmara de germinação, o híbrido AG 5011 apresentou variação na atividade inibidora de protease de 660,8; 966,9; 911,0; 1278,0 e 1818,8 UIP/g, correspondentes aos tempos de germinação 0 a 168 h (Figura 2). Entretanto, o resultado em condições de casa de vegetação diferiu, com 660,8; 721,$1713 ; 530,4 ; 720,0 ; 566,7$ e $1945,2 \mathrm{UIP} / \mathrm{g}$, correspondentes a 0, 24, 48, 72, 96 e $168 \mathrm{~h}$ (Figura 2).

O híbrido CD 307, em câmara de germinação mostrou atividade inibidora de protease evoluindo de 550,$0 ; 584,3 ; 1546,2 ; 3198,4$ e $3293,9 \mathrm{UIP} / \mathrm{g}$, correspondentes a 0, 24, 48, 72, 96 e 168 h (Figura 2). Todavia, sob umidade e temperatura não controladas (casa de vegetação) observou-se resposta diferente: 550,0;822,4; 1309,4; 1692,8; 1582,9 e 3633,9 UIP/g nos tempos de germinação 0 , 24, 48, 72, 96 e 168 h (Figura 2).

Os inibidores de protease controlam o fornecimento de fonte protéica, bloqueando proteínas hidrolíticas (COPELAND; Mc DONALD, 1995), fato este demonstrado pelas curvas de atividade inibidora de AG 5011 e CD 307, indicando tendência a um aumento gradativo da inibição do catabolismo de proteínas (Figura 2). Comportamento semelhante foi observado no híbrido AG 9010 (KADOZAWA, 2002). O aumento gradativo de UIP poderia atuar simultaneamente beneficiando a plântula de milho inibindo $F$. verticillioides.

A Tabela 1 apresenta a comparação de médias da atividade inibidora de amilase e protease dos híbridos AG 5011 e CD 307 no processo germinativo, porém sem considerar a germinação, sendo as médias comparadas pelo Teste de Tukey. A evolução da atividade inibidora de amilase e protease mostrou-se progressiva no decorrer da germinação (Tabela 2). O híbrido CD 307 apresentou-se com atividades inibidoras de amilase e de protease significativamente superiores ao híbrido AG 5011, sendo que sob condições controladas de umidade e temperatura, os híbridos apresentaram maiores médias de atividade (Tabela 2). 
Tabela 1. Atividades médias de inibidores de amilase e inibidores de protease entre os híbridos de milho AG 5011 e CD 307.

\begin{tabular}{lcc}
\hline \multicolumn{1}{c}{ Híbrido } & $\begin{array}{c}\text { Atividade inibidora de amilase média } \\
\text { (UIA/g) }\end{array}$ & $\begin{array}{c}\text { Atividade inibidora de protease média } \\
\text { (UIP/g) }\end{array}$ \\
CD 307 & $14,8^{\mathrm{a}}$ & $1570,1^{\mathrm{a}}$ \\
AG 5011 & $11,4^{\mathrm{b}}$ & $1114,5^{\mathrm{b}}$ \\
\hline
\end{tabular}

*Médias seguidas de mesma letra na mesma coluna não diferem significativamente entre si pelo teste de Tukey a $5 \%$ de probabilidade. $\mathrm{DMS}=2,8$

Tabela 2. Comparação de atividades de inibidores de amilase médias entre os tempos de germinação em câmara de germinação e em casa de vegetação.

\begin{tabular}{lcccc}
\hline $\begin{array}{c}\text { Tempos de } \\
\text { germinação }(\mathrm{h})\end{array}$ & \multicolumn{2}{c}{ Câmara de germinação } & \multicolumn{2}{c}{ Casa de vegetação } \\
\hline & UIA/g & UIP/g & UIA/g & UIP/g \\
0 & $5,4^{\mathrm{bA}}$ & $605,4^{\mathrm{dA}}$ & $5,4^{\mathrm{bA}}$ & $605,4^{\mathrm{dA}}$ \\
24 & $4,1^{\mathrm{bA}}$ & $775,6^{\mathrm{dA}}$ & $7,9^{\mathrm{bA}}$ & $771,8^{\mathrm{dAA}}$ \\
48 & $23,5^{\mathrm{aA}}$ & $1228,6^{\mathrm{AA}}$ & $8,4^{\mathrm{bB}}$ & $919,9^{\mathrm{bcdA}}$ \\
72 & $25,9^{\mathrm{aA}}$ & $1485,4^{\mathrm{AA}}$ & $5,2^{\mathrm{bB}}$ & $1074,8^{\mathrm{bcA}}$ \\
96 & $19,4^{\mathrm{aA}}$ & $1700,8^{\mathrm{bA}}$ & $5,2^{\mathrm{bB}}$ & $1206,4^{\mathrm{bB}}$ \\
168 & $26,6^{\mathrm{aA}}$ & $2943,9^{\mathrm{aA}}$ & $19,7^{\mathrm{BB}}$ & $2789,5^{\mathrm{aA}}$ \\
\hline
\end{tabular}

Médias seguidas de mesma letra minúscula na mesma coluna não diferem significativamente entre si pelo teste de Tukey a $5 \%$ de probabilidade, médias seguidas de mesma letra maiúscula na mesma linha não diferem significativamente entre si pelo teste de Tukey a 5\% de probabilidade.

DMS $_{\text {coluna CÂMARA DE GERMINAÇ̃̃o }}=10,1$, DMS $_{\text {linha CÂMARA DE GERMINAÇÃo }}=6,8$, DMS $_{\text {coluna CASA DE VEGETAÇ̃̃o }}=422,1$, DMS $_{\text {linha CASA }}$ DE VEGETAÇ̃̃o $=286,3$

O fato indicou a dependência das condições de temperatura e umidade ( $25^{\circ}$ 90-95\% UR) na atividade inibidora durante a germinação. As condições de temperatura e umidade em câmara de germinação podem ter sido favoráveis ao desenvolvimento de
Fusarium spp., que por sua vez estimularam o aumento da atividade inibidora (VELLUTI et al., 2000), sendo que em casa de vegetação a temperatura média atingiu $21^{\circ} \mathrm{C}$ (Figura 3), com ampla variação entre a mínima e máxima.

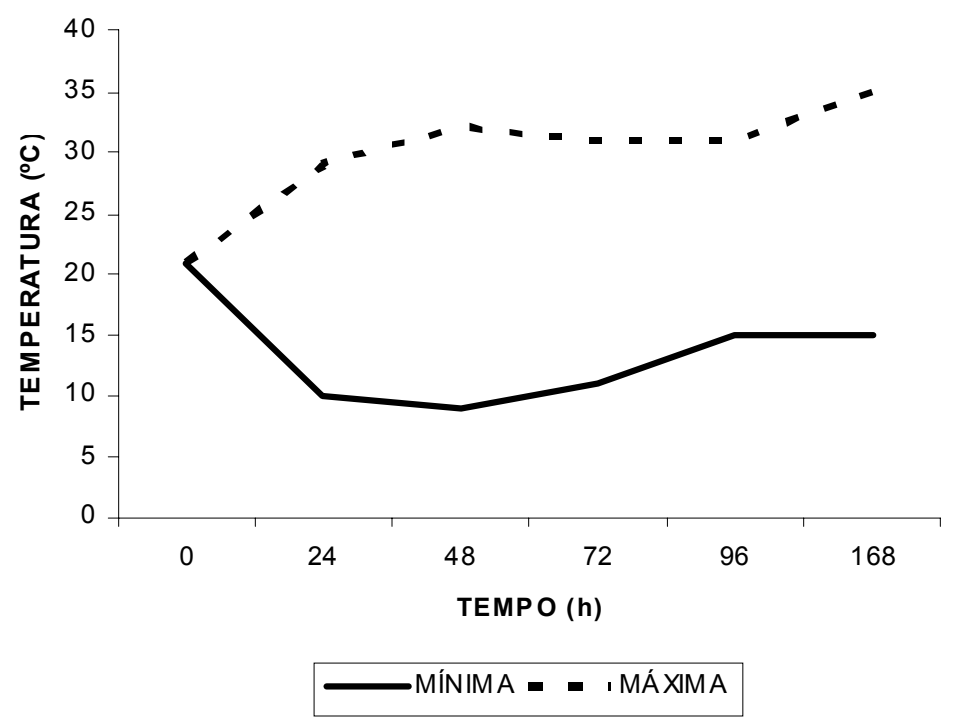

Figura 3. Temperatura mínima e máxima durante a germinação do milho em casa de vegetação. 
A resistência de milho contra fungos pode estar relacionada à presença de proteínas antifúngicas, envolvendo partes específicas de plântula (GUO et al., 1999). Na folha de milho ocorreu acúmulo de proteínas antifúngicas após a inoculação do patógeno (CORDERO et al., 1992). Em plântulas de feijão, a maior atividade dos inibidores de tripsina ocorreu nas folhas em relação aos cotilédones, aumentando conforme crescimento da plântula (WELHAM et al., 1998). A atividade inibidora de xilanase não foi detectada em coleóptilo e radícula de grãos germinados de trigo, indicando possível susceptibilidade perante $A$. niger (ELLIOTT et al., 2003).

A alta atividade inibidora de amilase, localizada no endosperma de milho germinado, pode estar relacionada à defesa da fonte energética. Em contrapartida, na radícula e coleóptilo, a menor atividade dos inibidores de amilase decorreu devido à alta atividade metabólica dos tecidos em desenvolvimento, e conseqüente maior susceptibilidade destas seções da plântula. Yates et al. (1997) observaram maior porcentagem de $F$. verticillioides em tecidos radiculares que em tecidos foliares, indicando maior susceptibilidade dos tecidos radiculares à infecção.

A análise das atividades inibidoras de protease nas diferentes partes da plântula do híbrido de milho CD 307 (192 h) detectou a atividade no coleóptilo, endosperma e radícula, com valor respectivo de 2255,$9 ; 1652,9$ e $1857,6 \mathrm{UIP} / \mathrm{g}$, porém não houve diferença significativa entre as médias. No endosperma de plântulas do híbrido CD 307 com 192 h de germinação ocorreu maior atividade inibidora, com 29,9 UIA/g. As médias da atividade inibidora de amilase no coleóptilo e radícula não apresentaram diferença significativa entre si, entretanto foram significativamente menores que a atividade no endosperma (Tabela 3).

Tabela 3. Atividade inibidora de amilase (UIA/g) e atividade inibidora de protease (UIP/g) em coleóptilo, endosperma e radícula de plântulas do híbrido CD 307 com 192 h de germinação em câmara de germinação $\left(25^{\circ} \mathrm{C}\right.$ e $90-95 \%$ UR).

\begin{tabular}{lcc}
\hline \multicolumn{1}{c}{ Partes da plântula } & \multicolumn{2}{c}{ Atividade inibidora } \\
\hline & UIA $/ \mathbf{g}$ & UIP/g \\
\cline { 2 - 3 } Coleóptilo & $14,3^{\mathrm{b}}$ & $2255,9^{\text {ns }}$ \\
Endosperma & $29,9^{\mathrm{a}}$ & $1652,9^{\text {ns }}$ \\
Radícula & $7,4^{\mathrm{b}}$ & $1857,6^{\mathrm{ns}}$ \\
Total & 17,2 & 1922,2 \\
\hline
\end{tabular}

Médias seguidas de mesma letra na mesma coluna não diferem significativamente entre si pelo teste de Tukey a $5 \%$ de probabilidade. $\mathrm{DMS}_{\mathrm{UIA}}=10,2$, ns=não significativo

Resistência dos hibridos de milho AG 5011 e $C D$ 307 contra S. zeamais

S. zeamais é o inseto que provoca mais prejuízos ao milho armazenado, aliado ao fato de facilitar a proliferação de fungos toxigênicos. A resistência de milho, baseada nos inibidores de amilase e protease, é uma ferramenta bastante promissora na redução da infestação de insetos no milho e conseqüente redução de fumonisinas.

O inibidor de amilase de 29,6 kDa extraído de milho por Blanco-Labra \& Itube-Chiñas (1981) atuou sobre amilase de S. zeamais, podendo exercer papel de resistência seja contra insetos ou fungos toxigênicos, sendo que os insetos propiciam condições favororáveis ao desenvolvimento fúngico. Sinha \& Sinha (1992) observaram maior ocorrência de $A$. flavus, assim como o nível de aflatoxinas em milho infestado.

Lara (1979) propôs o aumento do número total de insetos nascidos (geração F1), a redução do ciclo biológico e o aumento do índice de susceptibilidade de milho entre fatores diretamente relacionados à 
redução da resistência do híbrido ao inseto. O híbrido CD 307 apresentou menor ciclo biológico médio, indicando maior resistência à praga, enquanto que o híbrido AG 5011 apresentou maior índice de susceptibilidade, sugerindo maior resistência.

A Tabela 3 mostra as características avaliadas para resistência a $S$. zeamais e atividade inibidora contra enzimas de $F$. verticillioides nos híbridos de milho AG 5011 e CD 307 (tempo zero de germinação).

Os híbridos AG 5011 e CD 307 não foram significativamente diferentes para os parâmetros: número de insetos da geração $\mathrm{F} 1$, perda de peso dos grãos de milho e peso dos insetos (Tabela 4). O híbrido AG 5011 apresentou ciclo biológico médio de $S$. zeamais de 45,98, estatisticamente superior ao índice obtido por CD 307, portanto mais resistente ao inseto. O índice de susceptibilidade de milho, característica dependente dos resultados de ciclo biológico, peso de insetos emergidos, número de insetos emergidos e perda de peso dos grãos; indicou o híbrido AG 5011 como mais resistente ao inseto, apresentando índice de 9,49 (Tabela 4).

Tabela 4. Características avaliadas nos grãos dos híbridos de milho AG 5011 e CD 307 e em S. zeamais utilizadas como parâmetros para determinação da resistência dos híbridos ao inseto.

\begin{tabular}{|c|c|c|c|c|c|c|c|}
\hline \multirow{3}{*}{ Híbrido } & \multicolumn{5}{|c|}{ Resistência Contra $S$. zeamais } & \multirow{2}{*}{\multicolumn{2}{|c|}{$\begin{array}{l}\text { Atividade Inibidora Contra } \\
\text { Enzimas de } F \text {. verticillioides }\end{array}$}} \\
\hline & \multicolumn{3}{|c|}{ Características Avaliadas do Inseto } & \multicolumn{2}{|c|}{$\begin{array}{c}\text { Características Avaliadas do } \\
\text { Milho }\end{array}$} & & \\
\hline & $\begin{array}{c}\text { Número de } \\
\text { adultos } \\
\text { nascidos }\end{array}$ & $\begin{array}{c}\text { Ciclo } \\
\text { biológico } \\
\text { médio }(\mathrm{CB})\end{array}$ & $\begin{array}{l}\text { Peso dos } \\
\text { insetos } \\
\text { nascidos }\end{array}$ & $\begin{array}{l}\text { Perda de peso } \\
\text { dos grãos }\end{array}$ & $\begin{array}{l}\text { Indice de } \\
\text { susceptibi } \\
\text { lidade (IS) }\end{array}$ & $\begin{array}{c}\text { Atividade } \\
\text { inibidora de } \\
\text { amilase } \\
\text { (UIA/g) }\end{array}$ & $\begin{array}{l}\text { Atividade } \\
\text { inibidora de } \\
\text { protease } \\
\text { (UIP/g) }\end{array}$ \\
\hline AG 5011 & $79,0^{\mathrm{a}}$ & $45,9^{\mathrm{a}}$ & $2,9^{\mathrm{a}}$ & $3,5^{\mathrm{a}}$ & $9,5^{b}$ & $6,4^{\mathrm{a}}$ & $660,8^{\mathrm{a}}$ \\
\hline CD 307 & $85,7^{\mathrm{a}}$ & $44,7^{\mathrm{b}}$ & $3,0^{\mathrm{a}}$ & $4,3^{\mathrm{a}}$ & $9,9^{\mathrm{a}}$ & $4,4^{\mathrm{a}}$ & $550,0^{\mathrm{a}}$ \\
\hline
\end{tabular}

Médias seguidas de mesma letra na mesma coluna não diferem significativamente entre si pelo teste de Tukey a $5 \%$ de probabilidade. $\mathrm{DMS}_{\mathrm{CB}}=0,8, \mathrm{DMS}_{\mathrm{IS}}=0,4$.

A atividade inibidora de amilase e protease de milho apresentou-se aparentemente maior no híbrido AG 5011 (6,4 UIA/g e 660,8 UIP/g), se comparado ao $\mathrm{CD} 307$ (4,4 UIA/g e 550,0 UIP/g) (Tabela 4), indicando maior atividade inibidora contra enzimas de F. verticilliodes, bem como para resistência contra o inseto.

A atividade inibidora de amilase e protease apresentadas pelo $(0 \mathrm{~h})$ AG 5011 de 6,4 UIA/g e $660,8 \mathrm{UIP} / \mathrm{g}$ respectivamente, foram resultados superiores, porém não significativa, se comparado ao híbrido CD 307 (Tabela 4). Conseqüentemente, o híbrido AG 5011 apresentou maior atividade inibidora de amilase e protease que CD 307, indicando possível relação do índice de susceptibilidade do milho com inibidores de amilase e protease.
A atividade inibidora de amilase e protease apresentadas por AG 5011 (Tabela 1) o torna mais adequado para armazenamento, embora o híbrido CD 307 apresente maior resistência ao ataque de fitopatógenos no estágio inicial de desenvolvimento da planta. O estudo sobre proteínas de defesa visa contribuir no melhoramento genético, minimizando contaminação fúngica e conseqüente produção de micotoxinas.

\section{Conclusão}

A atividade inibidora de amilase e protease no grão de milho apresentou-se maior no híbrido $\mathrm{AG}$ 5011, quando comparado ao híbrido CD 307. Entretanto, o processo germinativo inverteu o perfil, 
com o híbrido CD 307 apresentando maior atividade inibidora contra amilase e protease de $F$. verticillioides.. Neste contexto, infere-se que as características de AG 5011 o tornam mais adequado para armazenamento, embora no estágio inicial de desenvolvimento da planta, o híbrido CD 307 apresente maior resistência ao ataque de fitopatógenos. As atividades inibidoras de amilase e protease constituem mecanismo natural de defesa da planta, cujo estudo aliado à resistência simultânea contra $F$. verticilliodes e insetos predadores confeririam características promissoras ao melhoramento genético de milho visando minimização da contaminação fúngica e produção de micotoxinas.

\section{Agradecimentos}

Os autores agradecem ao $\mathrm{CNPq}$ (Conselho Nacional de Desenvolvimento Científico e Tecnológico), SETI-Fundo Paraná e JICA (Japan International Cooperation Agency) pelo apoio financeiro. CAPES (Fundação Coordenação de Aperfeiçoamento de Pessoal de Nível Superior) e $\mathrm{CNPq}$ pela bolsa a Pós-graduandos e $\mathrm{CNPq} / \mathrm{Pq}$ a Elisa Yoko Hirooka e Ivone Yurika Mizubuti.

\section{Referências bibliográficas}

BLANCO-LABRA, A.; CHAGOLLA-LOPEZ, A.; MARTÍNEZ-GALLARDO, N.; VALDES-RODRIGUES, S. Further characterization of the $12 \mathrm{kDa}$ protease/alpha amylase inhibitor present in maize seeds. Journal of Food Biochemistry, v. 19, p. 27-41, 1995.

BLANCO-LABRA, A.; ITURBE-CHIÑAS, F.A. Purification and characterization of an alpha-amylase inhibitor from maize (Zea mays). Journal of Food Biochemistry. v. 5, p. $1-17,1981$.

CHEN, Z.Y.; BROWN, R.L.; CLEVELAND, T.E.; DAMANN, K.E.; RUSSIN, J.S. Comparison of constitutive and inducible maize kernel proteins of genotypes resistant or susceptible to aflatoxin production. Journal of Food Protection. v. 64, n. 11, p. 1785-1792, 2001.

COPELAND, L.O.; McDONALD, M.B. Principles of Seed Science and Technology. 3 edition, Chapman and Hall, 1995, p. 59-101.
CORDERO, M.J.; RAVENTÓS, D.; SAN SEGUNDO, B. Induction of PR proteins in germinating maize seeds infected with the fungus Fusarium verticillioides. Physiological and Molecular Plant Pathology, v. 41, p. 189-200, 1992.

ELLIOTT, G.O.; MCLAUCHLAN,W.R.; WILLIAMSON, G.; KROON, P.A.A.D. A wheat xylanase inhibitor protein (XIP-I) accumulates in the grain and has homologues in other cereals. Journal of Cereal Science. v. 37, n. 2, p. 187-194; 2003.

FAKHOURY, A.M.; WOLOSHUK, C.P. Inhibition of growth of Aspergillus flavus and fungal á-amylases by a lectinlike protein from Lablab purpureus. Molecular Plant Microbe interaction. n. 14, p. 955-961, 2001.

FIGUEIRA, E.L.Z.; BLANCO-LABRA, A.; GERAGE, A.C.; ONO, E.Y.S.; MENDIOLA-OLAYA, E.; UENO, Y; HIROOKA. E.Y. New Amylase Inhibitor Present in Corn Seeds Active In Vitro Against Amylase from Fusarium verticillioides. Plant Disease. v. 87, n. 3, p. 233-240, 2003 a.

FIGUEIRA, E.L.Z;; HIROOKA, E.Y.; MENDIOLA-OLAYA, E.; BLANCO-LABRA, A. Characterization of a hydrophobic amylase inhibitor from corn (Zea mays) seeds with activity

against amylase from Fusarium verticillioides. Phytopathology. v. 93, n. 8, p. 917-922, 2003 b.

GUO, B.Z.; CHEN, Z.Y.; BROWN, A.R.; LAX, T.E.; CLEVELAND, J.S.; RUSSIN, A.D.; METHA, A.D.; SELITRENNIKKOFF, C.P.; WIDSTROM, N.W. Germination induces accumulation of specific proteins and antifungal activities in corn kernels. Biochemistry and Cell Biology..v. 87, n. 11, p. 1174-1178, 1997.

GUO, B.Z.; CLEVELAND, T.E.; BROWN, R.L.; WINDSTROM, N.W.; LYNCH, R.E.; RUSSIN, J.S. Distribution of antifungal proteins in maize kernels tissues using immunochemistry. Journal of Food Protection, v. 62, n. 3, p. 295-299, 1999.

KADOZAWA, P. Inibidores de enzimas e compostos de defesa do milho (Zea mays) contra Fusarium verticillioides durante a germinação. Londrina: UEL, 2002, 42p.. Trabalho de Conclusão de Curso (graduação). Departamento de Ciências Agrárias, 2002.

KAKADE, M.L.; RACKIS, J.J.; Mc GHEE, J.E.; PUSKI, G. Determination of tripsin activity to soy products: a collaborative analysis of an improved procedure. Cereal Chemists, v.51, p.376-382, 1974.

LAFIS - Brasil : Agricultura Milho, 02/mai/2003 [on line]. Capturado em 20 de outubro de 2003. Disponível em http:/ /www.lafis.com.br/site2002/portugues/produtos/estudos/ demos/I055013P.DOC. 
LARA, F.M. Princípios de Resistência de Plantas a Insetos. Piracicaba: Ed. Livroceres, 1979. 207p.

LIU, K.; MARKAKIS, P. An improved colorimetric method for determining antitrypitic activities in soybean products. Cereal Chemists, v.66, p.415-422, 1989.

MUNKVOLD, G.P.; DESJARDINS, A.E. Fumonisins in maize can we reduce their occurence? Plant Disease. Saint Paul, v. 81, n. 6, p. 556-565, 1997.

ONO, E.S.Y.; SUGIURA, Y.; HOMECHIN, M.; KAMOGAE, M.; VIZZONI, E.; UENO, Y.; HIROOKA, E.Y. Effect of climatic conditions on natural mycoflora and fumonisins in freshly harvested corn of the State of Paraná, Brazil. Mycopathologia. v. 147, p. 75-87, 1999.

SINHA, K.K.; SINHA, A.K. Impact of stored grain pests on seed deterioration and aflatoxin contamination in maize. Journal of Stored Products Research. v.28, n. 3, p. 21-219, 1992.

UENO, Y. Risk of multi-exposure to natural toxins. Mycotoxins, n.50, p.13-22; 2000.

VELLUTI, A.; MARÍN, S.; GONZALEZ, R.; RAMOS, A.J.; SANCHIS, V. Fumonisin B1, zearalenona and deoxynivalenol production by Fusarium verticillioides, $F$. proliferatum and $F$. graminearum in mixed cultures on irradiated maize kernels. Journal of Science of Food and Agriculture. v. 81, p. 88-94, 2000.

WAQUIM, J.S. Regras para análise de sementes. Brasília: Ministério da Agricultura e Reforma Agrária, 365p., 1992.

WELHAM, T.; O”NEILL, M.O.; JOHNSON, S.; WANG, T.L.; DOMONEY, C. Expression patterns of genes encoding seed trypsin inhibitors in Pisum sativum. Plant Science. v. 131, p. 13-24, 1998.

WILSON, J.J.; INGLEDEW, W.M. Isolation and characterization of Schwanniomyces alluvius amylolitic enzymes. Applied and Environmental Microbiology, v. 44, n. 2, p. 301-307, 1982.

XAVIER FILHO, J. The biological roles of serine and cysteine proteinase inhibitors in plants. Revista Brasileira de Fisiologia Vegetal, v. 4, n. 1, p. 1-6, 1992.

YATES, I.E.; BACON, C.W.; HINTON, D.M. Effects of endophytic infection by Fusarium verticillioides on corn growth and cellular morphology. Plant Disease, v.7, n.81, p. 723-728, 1997. 